\title{
Assessment of Renal Biomarkers of Renal Function in Commercial Automobile Workers in Benin City, Edo State, Nigeria
}

\author{
Babatunde Ishola Gabriel Adejumo ${ }^{1 *}$, Kehinde Olawunmi Awelogun1, \\ Gregory Ashimedua Uchuno², Alaba Michael Emmanuel ${ }^{3}$, Uchechukwu Dimkpa4, \\ Kingsley Ifeanyichukwu Omosor ${ }^{5}$, Oladimeji Nasiru Abdulrahman ${ }^{6}$ \\ ${ }^{1}$ Medical Laboratory Science Department, University of Benin, Benin City, Nigeria \\ ${ }^{2}$ External Quality Assurance Department, Medical Laboratory Science Council of Nigeria, Abuja, Nigeria \\ ${ }^{3}$ Medical Laboratory Science Department, College of Health Sciences and Technology, Idah, Nigeria \\ ${ }^{4}$ Physiology Department, Nnewi Campus, Nnamdi Azikiwe University, Awka, Nigeria \\ ${ }^{5}$ Shalom Diagnostic Medical Laboratory, Warri, Nigeria \\ ${ }^{6}$ Medical Laboratory Science Department, College of Health Technology, Offa, , Nigeria \\ Email: ^babatunde.adejumo@uniben.edu, bigadejumo@yahoo.com
}

How to cite this paper: Adejumo, B.I.G., Awelogun, K.O., Uchuno, G.A., Emmanuel, A.M., Dimkpa, U., Omosor, K.I. and Abdulrahman, O.N. (2018) Assessment of Renal Biomarkers of Renal Function in Commercial Automobile Workers in Benin City, Edo State, Nigeria. Open Journal of Nephrology, 8, 18-28.

https://doi.org/10.4236/ojneph.2018.81003

Received: January 16, 2018

Accepted: March 19, 2018

Published: March 22, 2018

Copyright (c) 2018 by authors and Scientific Research Publishing Inc. This work is licensed under the Creative Commons Attribution International License (CC BY 4.0).

http://creativecommons.org/licenses/by/4.0/

\section{(c) () Open Access}

\begin{abstract}
Background: Blood-urea nitrogen, creatinine, uric acid and electrolytes are important biomarkers of renal function which could be considered as suitable prognostic indicators of renal dysfunction. Aim: The aim of this work was to assess renal biomarkers of renal function in commercial automobile workers in Benin City, Edo State, Nigeria. Methodology: A total of 158 males within the ages of $18-60$ years participated in this study, 50 of which are control subjects. They were recruited for this study from various workshops in Benin City, while controls are unexposed volunteers. Results: It was observed that serum uric acid, urea, creatinine, chloride and bicarbonate levels in all the exposed groups were significantly higher $(\mathrm{p}<0.05$ or $\mathrm{p}<0.01$ or $\mathrm{p}<0.001)$ compared with the non-exposed group. Apart from blood urea, the values of all the other biomarkers of renal function fell within normal reference range. However, there were no significant differences in all the renal biomarkers when compared among all the exposed groups. Conclusion: This study indicated greater levels of some renal biomarkers in automobile workers compared with the controls. In addition, blood urea levels were elevated above normal range of values. These findings suggest that the occupationally exposed automobile workers may be at risk of renal diseases. This calls for urgent need for policy formulation that will prevent the vulnerable groups from kidney damage.
\end{abstract}




\section{Keywords}

Automobile Workers, Renal Biomarkers, Benin City, Nigeria

\section{Introduction}

An occupational disease is any chronic ailment that occurs as a result of work or occupational activity. It is an aspect of occupational safety and health, typically identified when the disease is more prevalent in a given group of workers compared with the general population or with other groups of workers [1] [2]. The assessment of occupational diseases therefore provides models for understanding environmental diseases. For example kidney damage induced by heavy exposure to identifiable toxins in few workers indicates what to expect among the larger population exposed to low levels of such toxins dispersed in the larger environment [3]. For such a disease to be accurately diagnosed, its risk assessed and the right therapy adopted, researchers have developed and utilized biochemical markers to improve clinical outcomes. Creatinine, urea, uric acid and electrolytes estimation have been identified as routine analyses which are useful in assessment of normal functioning of kidneys [4].

It is common to find automobile workshops scattered all over major cities in Nigeria and these workshops have been identified as major sources of environmental pollution. Automobile workshop workers include those who are routinely engaged in activities such as auto mechanics, spray painting, panel beating, welding and battery recycling. It has been reported that these automobile workers are regularly exposed to auto lubricants, petroleum products, exhaust fumes and heavy metals such as lead, cadmium and chromium in their automobile workshops [5] [6] [7]. These toxicants may gain entrance into the body through inhalation, dermal contact and inadvertent ingestion and distributed throughout the body with the systemic effect occurring beyond the site of contact. Such exposures may pose great danger to the human body, particularly to organs associated with handling wastes such as the kidneys.

There is limited information on the renal functions of workers (automobile mechanics, automobile battery recyclers, and spray painters) occupationally exposed to lead and other environmental pollutants in Nigeria and Africa. The present study therefore was aimed at determining the possible effects of job exposure on renal biomarkers among these groups of workers in Benin City, Nigeria.

\section{Methods}

\subsection{Study Area}

This study was conducted in the Metropolitan City of Benin, Edo State, Nigeria. Historically, the residents are mainly civil servants and farmers, though appreciable population also indulge in trading and artisanship. With the influx of varieties of vehicles in early 2000 , the number of people engaged in manual repairs 
and maintenance of vehicles as source of livelihood increased. This created different categories of automobile activities within the city and the automobile workers are mostly illiterates with little or no formal education.

\subsection{Study Design}

A total of 158 apparently healthy males within the ages of 18 - 60 years participated in this study. The study population comprises 59 automobile mechanics, 18 battery recyclers, 21 spray painters (Table 1) selected from auto-mobile workshops around Ugbowo, Uselu, Ekehuan, New Benin and University of Benin, all within Benin metropolis. Fifty age-matched unexposed volunteers, who were staff and students of University of Benin, served as controls. Exclusion criteria included history of hypertension and kidney diseases $(n=10)$. The ethics committee of Ministry of Health, Edo State, as well as heads of the various automobile workshops approved this study. The personal consents of the participants were sought after explaining the purpose of the research. A questionnaire was administered to every participant of this study for demographic information.

\subsection{Sample Processing}

Five millilitres of blood were collected from each participant and dispensed into a plain container. The non anticoagulated blood was spun at $1500 \mathrm{rpm}$ for 10 minutes and the supernatant serum was separated immediately into separate tubes. The serum was stored at $-20^{\circ} \mathrm{C}$ for up to 2 weeks prior to the analysis. Iron Selective Electrolytes (ISE 4000) by SFRI equipment (France) was used for the analysis of electrolytes, while analysis of different biochemical parameters was done using VIS-7220G spectrophotometer from Biotech Engineering Company Limited (UK) according to the procedure given in the kit protocol.

\subsection{Electrolytes and Biochemical Analysis}

Some electrolytes and biochemical parameters were measured to ascertain the renal status of the automobile mechanics, automobile battery chargers, spray painters and controls. These include Sodium, Potassium, Bicarbonate and Chloride, Urea, Creatinine and Uric acid. The Sodium, Potassium, Bicarbonate and Chloride levels were estimated using Iron Selective Electrolytes (ISE 4000) by

Table 1. Study population.

\begin{tabular}{ccc}
\hline Subject & Number & Percentage \\
\hline Automobile mechanics & 59 & 39.9 \\
Battery recycler (battery chargers) & 18 & 12.2 \\
Spray painters & 21 & 14.2 \\
Control (Staff and students of University of Benin) & 50 & 33.8 \\
Total & 148 & 100
\end{tabular}


SFRI equipment (France) together with the commercially prepared reagents from the manufacturer. Urea, creatinine and uric acid levels were estimated using reagent kits from Randox Diagnostic Company Limited, (UK) as described by the manufacturer.

\subsection{Data Analysis}

Data was expressed as mean and standard deviation. Comparative analysis involving two groups was done using independent sample t-test, while those involving more than two groups were done using one-way analysis of variance (ANOVA). T-statistics provided a measure of the probability that there is a significant difference between the two groups, while the F-statistics indicated strength of significant differences among three groups. Statistical significance was set at $\mathrm{p}<0.05$. All statistics were done using IBM/SPSS software (version 20.0).

\section{Results}

Table 2 shows the mean levels of renal biomarkers of mechanics compared to those of controls. Data indicated lack of significant differences in sodium between the mechanics and the controls. In contrast, the mechanics indicated significantly greater chloride $(\mathrm{p}<0.001)$, bicarbonate $(\mathrm{p}<0.001)$, blood urea nitrogen $(\mathrm{p}<0.01)$, creatinine $(\mathrm{p}<0.05)$ and uric acid $(\mathrm{p}<0.001)$ but lower potassium $(\mathrm{p}<0.05)$ compared to the controls.

Table 3 shows the mean levels of renal biomarkers of battery chargers compared to those of controls. Data indicated lack of significant differences in sodium and potassium between the battery chargers and the controls. In contrast, the battery chargers indicated significantly greater chloride $(\mathrm{p}<0.001)$, bicarbonate $(\mathrm{p}<0.01)$, blood urea $(\mathrm{p}<0.05)$, creatinine $(\mathrm{p}<0.01)$ and uric acid $(\mathrm{p}<$ $0.001)$ compared to the controls.

Table 4 shows the mean levels of renal biomarkers of spray painters compared to those of controls. Data indicated lack of significant differences in sodium, potassium and creatinine between the spray painters and the controls. In contrast, the spray painters indicated significantly greater chloride $(\mathrm{p}<0.001)$, bicarbonate $(\mathrm{p}<0.01)$, blood urea $(\mathrm{p}<0.05)$ and uric acid $(\mathrm{p}<0.001)$ compared to the controls.

Table 5 shows the mean levels of renal biomarkers compared among the three automobile professional groups. Data indicated lack of significant differences in sodium, potassium, chloride, bicarbonate, urea, creatinine and uric acid among the three groups.

\section{Discussion}

Automobile mechanics, spray painters and battery chargers are exposed to residual used gasoline engine oils (UGEO), gasoline, gasoline-based paint spray, jet fuel and mineral turpentine that accumulate on automobile parts, tools, work 
Table 2. Mean levels of renal biomarkers of mechanics compared to the controls.

\begin{tabular}{ccccc}
\hline Variables & Controls $(\mathrm{n}=50)$ & Mechanics $(\mathrm{n}=59)$ & t-statistics & p-value \\
\hline Sodium $(\mathrm{mmol} / \mathrm{L})$ & $136.50 \pm 2.21$ & $137.74 \pm 4.43$ & -1.80 & 0.074 \\
Potassium (mmol/L) & $3.77 \pm 0.19$ & $3.64 \pm 0.33$ & 2.58 & 0.011 \\
Chloride (mmol/L) & $100.30 \pm 2.56$ & $105.63 \pm 3.37$ & -9.15 & 0.000 \\
Bicarbonate (mmol/L) & $20.36 \pm 2.70$ & $23.88 \pm 5.50$ & -4.12 & 0.000 \\
Blood Urea Nitrogen (mg/dl) & $20.18 \pm 4.40$ & $27.41 \pm 14.85$ & -3.32 & 0.001 \\
Creatinine (mg/dl) & $0.82 \pm 0.24$ & $0.95 \pm 0.35$ & -2.25 & 0.026 \\
Uric Acid (mg/dl) & $4.02 \pm 0.67$ & $5.89 \pm 1.45$ & -8.33 & 0.000 \\
\hline
\end{tabular}

Table 3. Mean levels of renal biomarkers of battery chargers compared to the controls.

\begin{tabular}{ccccc}
\hline Variables & Controls $(\mathrm{n}=50)$ & Battery Chargers $(\mathrm{n}=18)$ & t-statistics & p-value \\
\hline Sodium $(\mathrm{mmol} / \mathrm{L})$ & $136.50 \pm 2.21$ & $137.0 \pm 3.86$ & -0.66 & 0.509 \\
Potassium $(\mathrm{mmol} / \mathrm{L})$ & $3.77 \pm 0.19$ & $3.67 \pm 0.34$ & 1.46 & 0.148 \\
Chloride $(\mathrm{mmol} / \mathrm{L})$ & $100.30 \pm 2.56$ & $105.44 \pm 3.22$ & -6.81 & 0.000 \\
Bicarbonate $(\mathrm{mmol} / \mathrm{L})$ & $20.36 \pm 2.70$ & $23.66 \pm 5.40$ & -3.34 & 0.001 \\
Blood Urea Nitrogen (mg/dl) & $20.18 \pm 4.40$ & $27.38 \pm 21.79$ & -2.24 & 0.028 \\
Creatinine (mg/dl) & $0.82 \pm 0.24$ & $1.03 \pm 0.26$ & -3.07 & 0.003 \\
Uric Acid (mg/dl) & $4.02 \pm 0.67$ & $5.87 \pm 1.35$ & -7.53 & 0.000 \\
\hline
\end{tabular}

Table 4. Mean levels of renal biomarkers of spray painters compared to the controls.

\begin{tabular}{ccccc}
\hline Variables & Controls $(\mathrm{n}=50)$ & Spray Painters $(\mathrm{n}=21)$ & t-statistics & p-value \\
\hline Sodium $(\mathrm{mmol} / \mathrm{L})$ & $136.50 \pm 2.21$ & $137.76 \pm 4.75$ & -1.53 & 0.130 \\
Potassium $(\mathrm{mmol} / \mathrm{L})$ & $3.77 \pm 0.19$ & $3.71 \pm 0.38$ & 0.89 & 0.374 \\
Chloride $(\mathrm{mmol} / \mathrm{L})$ & $100.30 \pm 2.56$ & $106.04 \pm 3.44$ & -7.76 & 0.000 \\
Bicarbonate $(\mathrm{mmol} / \mathrm{L})$ & $20.36 \pm 2.70$ & $23.95 \pm 6.19$ & -3.42 & 0.001 \\
Blood Urea Nitrogen (mg/dl) & $20.18 \pm 4.40$ & $24.71 \pm 10.47$ & -2.58 & 0.012 \\
Creatinine (mg/dl) & $0.82 \pm 0.24$ & $0.92 \pm 0.29$ & -1.40 & 0.164 \\
Uric Acid (mg/dl) & $4.02 \pm 0.67$ & $5.80 \pm 1.22$ & -7.90 & 0.000 \\
\hline
\end{tabular}

Table 5. Mean levels of renal biomarkers compared among the three automobile professional groups.

\begin{tabular}{cccccc}
\hline Variables & Mechanics $(\mathrm{n}=59)$ & Battery Chargers $(\mathrm{n}=18)$ & Spray Painters $(\mathrm{n}=21)$ & F-statistics & $\mathrm{p}$-value \\
\hline Sodium (mmol/L) & $137.74 \pm 4.43$ & $137.0 \pm 3.86$ & $137.76 \pm 4.75$ & 0.21 & 0.809 \\
Potassium (mmol/L) & $3.64 \pm 0.33$ & $3.67 \pm 0.34$ & $3.71 \pm 0.38$ & 0.39 & 0.676 \\
Chloride (mmol/L) & $105.63 \pm 3.37$ & $105.44 \pm 3.22$ & $106.04 \pm 3.44$ & 0.18 & 0.838 \\
Bicarbonate (mmol/L) & $23.88 \pm 5.50$ & $23.66 \pm 5.40$ & $23.95 \pm 6.19$ & 0.01 & 0.986 \\
Blood Urea Nitrogen (mg/dl) & $27.41 \pm 14.85$ & $27.38 \pm 21.79$ & $24.71 \pm 10.47$ & 0.24 & 0.783 \\
Creatinine (mg/dl) & $0.95 \pm 0.35$ & $1.03 \pm 0.26$ & $0.92 \pm 0.29$ & 0.63 & 0.535 \\
Uric Acid (mg/dl) & $5.89 \pm 1.45$ & $5.87 \pm 1.35$ & $5.80 \pm 1.22$ & 0.03 & 0.969 \\
\hline
\end{tabular}


benches, floors and equipment [8] [9]. The association between occupational exposure to toxic chemicals, gout and renal function impairment is well-known [10] [11] [12].

In this study, the levels of renal biomarkers were assayed in occupationally exposed automobile mechanics, battery chargers and spray painters who are persistently and chronically exposed to toxic metals. Results indicated that serum uric acid, blood urea nitrogen, creatinine, and electrolytes such aschloride and bicarbonate levels were elevated and higher in the exposed groups compared with the controls. It is noteworthy that the automobile workers indicated values which fell within the normal reference values for serum uric acid (3.4 - 7.0 $\mathrm{mg} / \mathrm{dl})$, creatinine $(0.8-1.3 \mathrm{mg} / \mathrm{dl})$, sodium $(135-145 \mathrm{mmol} / \mathrm{L})$, potassium $(3.5$ - $5.0 \mathrm{mmol} / \mathrm{L})$, chloride $(98-106 \mathrm{mmol} / \mathrm{L})$ and bicarbonate $(23-30 \mathrm{mmol} / \mathrm{L})$. However, mean blood urea nitrogen values were above the normal range of 8 $21 \mathrm{mg} / \mathrm{dl}$ in all the automobile workers (mechanics, $27.41 \mathrm{mg} / \mathrm{dl}$; battery chargers, $27.38 \mathrm{mg} / \mathrm{dl}$; spray painters, $24.71 \mathrm{mg} / \mathrm{dl}$ ).

Previous studies by Pinto de Almeida et al. [13], Weaver et al. [14] and Ahmed et al. [15] have reported higher serum uric acid levels in occupationally-exposed subjects compared to controls. Endo, et al. [16], Jung, et al. [17] and Wang, et al. [18] also found significantly higher mean serum urea levels in occupationally-exposed subjects compared to controls. Patil et al. [19] has also reported significant increase in blood urea among battery manufacturing workers. Increases in liver functional biomarkers were found in an occupational study of metal-exposed paint workers [20]. Higher mean serum creatinine level has been reported in occupationally exposed workers compared with unexposed workers [21]. Similarly, Pergande, et al. [22] reported that creatinine clearance was significantly lower in toxic metals-exposed workers compared to controls. We could not find previous studies reporting changes in electrolyte levels in blood of occupationally exposed automobile workers. With regards to the present findings, no previous study, to the best of our knowledge, has shown higher chloride or bicarbonate levels in automobile workers compared with non-automobile controls. However, a previous study [23] has shown lack of significant differences in sodium and potassium levels in blood of selected industrial workers in Ewekoro, Abeokuta, Ogun state Nigeria. This finding is similar to results obtained in the present data for sodium in mechanics, battery recyclers and automobile spray painters; and data for potassium in battery chargers and spray painters, but contrasts with the lower potassium levels in the mechanic group.

The mechanisms behind the higher mean serum uric acid, urea, creatinine, chloride and bicarbonate levels in automobile workers in this study are not very clear. However, previous studies have associated elevated levels of some of these renal biomarkers with exposure to lead. For example, Dioka et al., [24] reported that occupational exposure of human subjects to lead in petrol increases the concentrations of uric acid in the exposed subjects compared with unexposed 
subjects. Similarly, Hernandez Serrato et al. [25] found that hyperuricemia was associated with blood lead concentrations above 40 microg/dL. Wang et al. [18] reported significant increase in uric acid blood urea and serum creatinine levels among lead battery workers with exposure to lead. Erhlich, et al. [21] reported elevated serum creatinine level in South African lead-exposed workers. Lead is recognized as an environmental and occupational pollutant [26] [27] and automobile repair works involving battery lead-acid recycling, automobile radiator repair, and auto-mechanic repair and welding have been identified as common sources of lead exposure [15].

Blood-urea nitrogen, creatinine and uric acid could be considered as suitable prognostic indicators of renal dysfunction in lead-exposed workers [18]. Uric acid is the end-product of endogenous and dietary purine metabolism in humans. It is formed by the liver and mainly excreted by the kidneys. An elevation of circulating serum uric acid is strongly associated with hypertension and renal disease [28]. Urea is a waste product of metabolism that is excreted by the kidneys in urine. Reduced urea excretion and consequent rise in blood concentration is associated with kidney disease [29]. Creatinine is produced in muscle by the non-enzymatic conversion of creatine and phosphocreatinine, synthesized primarily in the liver from the methylation of guanidine aminoacetic acid and removed from the blood chiefly by the kidneys, primarily by glomerular filtration, but also by proximal tubular secretion. An elevation in the serum creatinine concentration usually reflects a reduction in the glomerular filtration rate [30]. It is the most commonly used indicator of renal function [31]. The present findings indicating elevated blood urea above normal range, and higher creatinine and uric acid in the automobile workers therefore suggest that these workers may be at risk of renal dysfunction.

The higher mean bicarbonate levels observed in all the automobile groups may be a renal compensation which occurs to lessen the effect of hypoventilation, which causes hypercapnia, and results in acid-base disorders such as respiratory acidosis. Auto-mobile workers are regularly exposed to environmental pollutants such as dust, used auto lubricants, petroleum products, exhaust fumes and prone to long-term lead toxicity, which are associated with cardiovascular, respiratory and urinary diseases [5] [8]. Respiratory acidosis may also result from reduced efficiency of the kidneys to remove acids from the blood in proximal renal tubular dysfunction due to high level of blood cadmium [32].The higher chloride observed in all the auto-mobile workers compared with the controls may be associated with exposure to cadmium. Elevated chloride level has been shown to be a side effect of elevated blood cadmium levels [32]. Previous studies [33] [34] have also reported greater blood cadmium levels in auto mechanics, spray painters, and battery recyclers. This is due to the fact that Cadmium is a common component of spray paint pigment (cadmium yellow), welding fume and cadmium containing batteries [35] [36]. It is noteworthy to state that though these auto-mobile workers had values of these electrolytes 
within normal range; the higher levels observed in their blood relative to the controls may be indicative of gradual progression to associated kidney disorders.

This study further demonstrates that the higher blood levels of the renal biomarkers observed in automobile workers relative to unexposed subjects may be influenced by their occupational practices, lack of protection against workplace toxic metals and environmental pollutants. As observed in this study, high degree of exposure to toxic substances may be particularly due to the occupational lifestyle of the workers which shows high level of primitiveness and near zero safety practices. This was reflected from the information gathered from the participants, only $2 \%$ of them use protective devices frequently, while $40 \%$ use occasionally and 58\% do not use. By observational assessment of the work place, it was observed that all areas were semi-closed with no adequate ventilation, which meant that workers especially the automotive spray painters' exposure to solvents may have exceeded the threshold limit value recommended for the mixture by the American Conference of Governmental Industrial Hygienists (ACGIH).

\section{Conclusion}

In conclusion, the present study indicated elevated renal biomarkers among the occupationally exposed automobile workers, which may put these workers at high risk of renal impairment. There is therefore the need for government to formulate policy to guide these groups of workers on ethics and rules guiding workplace, the use of both face and hand protectors, and to work in a clean and ventilated environment.

\section{Acknowledgements}

We acknowledge the Ministry of Health, Edo State for ethical approval, and all the participants within Benin City.

\section{Conflicts of Interest}

None.

\section{Funds}

The research was privately funded. No grant or sponsorship from anywhere.

\section{References}

[1] Al-Ghamdi, S.S. (2011) Occupational Exposure to Paints Causes Impairment of Kidney Functions. Journal of Environmental Protection, 2, 533-536. https://doi.org/10.4236/jep.2011.25061

[2] Anetor, J.I., Akingbola, T.S., Adeniyi, F.A.A. and Taylor, G.O. (2005) Decreased total and Ionized Calcium Levels and Haematological Indices in Occupational Lead Exposure as Evidence of the Endocrine Disruptive Effect of Lead. Indian Journal of Occupational and Environmental Medicine, 9, 15-21. https://doi.org/10.4103/0019-5278.16036

[3] Wedeen, R. (1997) Occupational and Environmental Renal Disease. Seminars in 
Nephrology, 17, 46-53.

[4] Gowda, S., Desai, P.B., Kulkarni, S.S., Hull, V.V., Math, A.A.K. and Vernekar, S.N. (2010) Markers of Renal Function Tests. North American Journal of Medical Sciences, 2, 170-173.

[5] Boritz, Z.S., Michael, T.K. and Robert, A.K. (2008) Air Pollution and Cardiovascular Injury. Journal of the American College of Cardiology, 52, 719-726. https://doi.org/10.1016/j.jacc.2008.05.029

[6] Adela, Y, Ambelu, A. and Tessema, D.A. (2012) Occupational Lead Exposure among Automotive Garage Workers-A Case Study for Jimma Town, Ethiopia. Journal of Occupational Medicine and Toxicology, 7, 15. https://doi.org/10.1186/1745-6673-7-15

[7] Vitayavirasuk, B., Junhom, S. and Antisaeranee, P.T. (2005) Exposure to Lead, Cadmium and Chromium among Spray Painters in Automobile Body Repair Shops. Journal of Occupational Health, 47, 518-522 https://doi.org/10.1539/joh.47.518

[8] Boffetta, P., Jourenkova, N. and Gustavsson, P. (1997) Cancer Risk from Occupational and Environmental Exposure to Polycyclic Aromatic Hydrocarbons. Cancer Causes \& Control, 8, 444-472. https://doi.org/10.1023/A:1018465507029

[9] Ahmad, M. (2001) Essentials of Medical Biochemistry. Merit Publishers, Multan, p. 1022.

[10] Batuman, V. (1993) Lead Nephropathy, Gout, and Hypertension. The American Journal of the Medical Sciences, 305, 241-247. https://doi.org/10.1097/00000441-199304000-00008

[11] Shadick, N.A., Kim, R. and Weiss, S. (2000) Effect of Low Level Lead Exposure on Hyperuricemia and Gout among Middle Aged and Elderly Men: The Normative Aging Study. The Journal of Rheumatology, 27, 1708-1712.

[12] Lin, J.L., Tan, D.T., Ho, H.H. and Yu, C.C. (2002) Environmental Lead Exposure and Urate Excretion in the General Population. The American Journal of Medicine, 113, 563-568. https://doi.org/10.1016/S0002-9343(02)01296-2

[13] Pinto de Almeida, A.R., Carvalho, F.M., Spinola, A.G. and Rocha, H. (1987) Renal Dysfunction in Brazilian Lead Workers. American Journal of Nephrology, 7, 455-458. https://doi.org/10.1159/000167519

[14] Weaver, V.M., Jaar, B.G. and Schwartz, B.S. (2005) Associations among Lead Dose Biomarkers, Uric Acid, and Renal Function in Korean Lead Workers. Environmental Health Perspectives, 113, 36-42. https://doi.org/10.1289/ehp.7317

[15] Ahmed, K., Ayana, G. and Engidawork, E. (2008) Lead Exposure Study among Workers in Lead Acid Battery Repair Units of Transport Service Enterprises, Addis Ababa, Ethiopia: A Cross-Sectional Study. Journal of Occupational Medicine and Toxicology, 3, 30. https://doi.org/10.1186/1745-6673-3-30

[16] Endo, G., Horiguchi, S. and Kiyota, I. (1990) Urinary N-acetyl-beta-D Glucosaminidase Activity in Lead-Exposed Workers. Journal of Applied Toxicology, 10, 235-345. https://doi.org/10.1002/jat.2550100402

[17] Jung, K.Y., Lee, S.J. and Kim, J.Y. (1998) Renal Dysfunction Indicators in Lead Exposed Workers. Journal of Occupational Health, 40, 103-109. https://doi.org/10.1539/joh.40.103

[18] Wang, V.S., Lee, M.T. and Chiou, J.Y. (2002) Relationship between Blood Lead Levels and Renal Function in Lead Battery Workers. International Archives of Occupational and Environmental Health, 75, 569-575. https://doi.org/10.1007/s00420-002-0362-0 
[19] Patil, A.J., Bhagwat, V.R., Patil, J.A., Dongre, N.N., Ambekar, J.G. and Das, K.K. (2007) Occupational Lead Exposure in Battery Manufacturing Workers, Silver Jewelry Workers, and Spray Painters in Western Maharashtra (India): Effect on Liver and Kidney Function. Journal of Basic and Clinical Physiology and Pharmacology, 18, 87-100. https://doi.org/10.1515/JBCPP.2007.18.2.87

[20] Orisakwe, O.E., Nwachukwu, E., Osadolor, H.B., Afonne, O.J. and Okocha, C.E. (2007) Liver and Kidney Function Tests amongst Paint Factory Workers in Nkpor, Nigeria. Toxicology and Industrial Health, 23, 161-165.

https://doi.org/10.1177/0748233707081908

[21] Ehrlich, R., Robins, T. and Jordaan, E. (1998) Lead Absorption and Renal Dysfunction in a South African Battery Factory. Occupational and Environmental Medicine, 55, 453-460. https://doi.org/10.1136/oem.55.7.453

[22] Pergande, M., Jung, K. and Precht, S. (1994) Changed Excretion of Urinary Proteins and Enzymes by Chronic Exposure to Lead. Nephrology Dialysis Transplantation, 9, 613-618. https://doi.org/10.1093/ndt/9.6.613

[23] Babalola, O.O. and Babajide, S.O. (2009) Selected Heavy Metals and Electrolyte Levels in Blood of Workers and Residents of Industrial Communities. African Journal of Biochemistry Research, 3, 37-40.

[24] Dioka, C.E., Orisakwe, O.E., Adeniyi, F.A.A. and Meludu, S.C. (2004) Liver and Renal Function Tests in Artisans Occupationally Exposed to Lead in Mechanic Village in Nnewi, Nigeria. International Journal of Environmental Research and Public Health, 1, 21-25. https://doi.org/10.3390/ijerph2004010021

[25] Hernandez-Serrato, M.I., Fortoul, T.I., Rojas-Martinez, R., Mendoza-Alvarado, L.R., Canales-Trevino, L., Bochichio-Riccardelli, T., Avila-Costa, M.R. and Olaiz-Fernandez, G. (2006) Lead Blood Concentrations and Renal Function Evaluation: Study in an Exposed Mexican Population. Environmental Research, 100, 227-233. https://doi.org/10.1016/j.envres.2005.03.004

[26] WHO (2010) WHO Childhood Lead Poisoning. World Health Organization, Geneva.

[27] Pourmand, A., Al-tiae, T.K. and Amirshahi, M.M. (2012) Perspective on Lead Toxicity, a Comparison between the United States and Iran. DARU Journal of Pharmaceutical Sciences, 20, 1-6. https://doi.org/10.1186/2008-2231-20-70

[28] Mazzali, M., Hughes, J., Kim, Y.G., Jefferson, J.A., Kang, D.H., Gordon, K.L., Lan, H.Y., Kivlighn, S. and Johnson, R.J. (2001) Elevated Uric Acid Increases Blood Pressure in the Rat by a Novel Crystal-Independent Mechanism. Hypertension, 38, 1101-1106.

[29] Higgins, C. (2016) Urea and the Clinical Value of Measuring Blood Urea Concentration.

https://acutecaretesting.org/en/articles/urea-and-the-clinical-value-of-measuring-bl ood-urea-concentration

[30] Samra, M. and Abcar, A.C. (2012) False Estimates of Elevated Creatinine. The Permanente Journal, 16, 51-52. https://doi.org/10.7812/TPP/11-121

[31] Howard, T.E. (1989) Clinical Chemistry. John Wiley and Sons, New York, 4, 58-62.

[32] Vallero, D. (2011) Biochemical Ethics for Engineers: Ethics and Decision Making in Biomedical and Biosystem Engineering. Elsevier, Amsterdam, 76.

[33] Khan, A.A., Inam, S., Idrees, M., Dad, A., Gul, K. and Akbar, H. (2010) Effect of Automobile Workshop on the Health Status of Automechanics in N. W. F. P., Pakistan. African Journal of Environmental Science and Technology, 4, 192-200. 
[34] Alli, L.A. (2015) Blood Level of Cadmium and Lead in Occupationally Exposed Persons in Gwagwalada, Abuja, Nigeria. Interdisciplinary Toxicology, 8, 146-150. https://doi.org/10.1515/intox-2015-0022

[35] International Agency for Research on Cancer (IARC) (1993) Monographs Cadmium. Lyon.

[36] Paschal, D.C., Burt, V., Caudill, S.P., Gunter, E.W., Pirkle, J.L., Sampson, E.J., et al. (2000) Exposure of the U.S. Population Aged 6 Years and Older to Cadmium: 1988-1994. Archives of Environmental Contamination and Toxicology, 38, 377-383. https://doi.org/10.1007/s002449910050 